\title{
A complementaridade dos pensamentos narrativo e matemático na gestação da teoria da Relatividade Geral ${ }^{+*}$
}

\author{
Danilo Cardoso ${ }^{1}$ \\ Doutorando do Programa Interunidades em Ensino de Ciências - USP \\ Ivã Gurgel ${ }^{2}$ \\ Instituto de Física - Universidade de São Paulo \\ São Paulo - SP
}

\section{Resumo}

Este trabalho investiga o papel de linguagens e pensamentos envolvidos nos processos de criação científica. É destacada a relevância da Matemática na Física. Mas qual é o papel epistemológico desempenhado por ela na construção da Física? O cientista é capaz de interpretar fisicamente a natureza somente usando linguagens e pensamentos formais, especialmente estruturados pela matemática? Nossa hipótese é que a resposta a essa questão é negativa. Encontramos nas ideias do psicólogo Jerome Bruner uma forma de encaminhar nossa discussão. A partir das ideias deste autor, e do nosso anseio por investigar o papel de pensamentos e linguagens que não são estritamente formais na construção da física, levantamos a seguinte questão: Qual o papel das narrativas e da matemática na construção da física? Para delinear uma resposta possível a esta questão, tomamos como contexto da nossa pesquisa alguns "capítulos" da construção da Teoria da Relatividade Geral. Nossa investigação mostrou que experimentos mentais importantes no desenvolvimento desta teoria foram construídos a partir dos pensamentos narrativo e matemático. Entendemos que estes dois modos de pensamentos se apresentaram de maneira complementar no contexto estudado.

Palavras-chave: Narrativas; Matemática; Relatividade Geral.

\footnotetext{
+ The complementarity of the narrative and mathematical thoughts in the development of General Theory of Relativity

* Recebido: dezembro de 2016. Aceito: junho de 2017.

${ }^{1}$ E-mail: danilo.cardoso.fis@gmail.com, ${ }^{2}$ E-mail: gurgel@if.usp.br
} 


\begin{abstract}
This work investigates the role of languages and thoughts involved in the processes of scientific creation. The relevance of Mathematics in Physics is highlighted. But what is the epistemological role played by Mathematics in the construction of Physics? Is the scientist able to physically interpret nature only by using formal languages and thoughts, especially structured by mathematics? Our hypothesis is that the answer to this question is negative. We find in the ideas of the psychologist Jerome Bruner a way to take our discussion forward. From the ideas of this author and our will to investigate the role of non-formal thoughts and languages in the construction of Physics, the following question was raised: What is the role of narratives and Mathematics in the construction of Physics? To delineate a possible answer to this question, we take as context of our research some "chapters" of the construction of the General Theory of Relativity. Our research has shown that important mental experiments in the development of this theory were built from the narrative and mathematical thoughts. We understand that both thoughts were present in the context studied, in a complementary way.
\end{abstract}

Keywords: Narratives; Mathematics; General Relativity.

\title{
I. Introdução
}

A área de pesquisa em Ensino de Ciências vem se consolidando como área social de produção de conhecimento ao longo das últimas décadas. Como área de amplo interesse, surgiram diversos enfoques, diferentes temáticas, empregando múltiplas metodologias de pesquisa e variados tipos de fundamentações teóricas (SALEM, 2012). Dentre as temáticas presentes na pesquisa em ensino de ciências, há aquela interessada em investigar o papel da linguagem no processo de ensino-aprendizagem (ESPINET et al., 2012, p. 1385). Há diferentes perspectivas que aproximam as questões da linguagem às investigações em ensino de ciências ${ }^{2}$, tais como: linguagem como produto do pensamento, caráter metafórico da linguagem, linguagem como ferramenta, uso de textos em aulas de ciências, entre outras (FLÔR; CASSIANI, 2011). Ainda que consideremos essa pluralidade de perspectivas, algo que parece perpassar essas pesquisas é a defesa de que "o domínio de uma matéria especializada como a ciência é em grande medida o domínio de suas formas especializadas de utilização da linguagem” (LEMKE, 1997, p. 37).

\footnotetext{
2 Para um panorama geral sobre as diferentes perspectivas de trabalhos sobre linguagem no ensino de ciências ver: "O que dizem os estudos da linguagem na educação científica?" (FLÔR; CASSIANI, 2011)
} 
Neste contexto, pode-se justificar a necessidade de buscarmos compreensões da linguagem não apenas no contexto de sala de aula (interação/comunicação; desenvolvimento cognitivo etc.), mas também investigar como se dá o funcionamento da linguagem na própria produção científica. Podemos denominar este tipo de pesquisa como uma abordagem epistemológica, que se interessa pela "produção linguística" dos cientistas, isto é, em como eles produzem novas maneiras de falar na busca por compreender a natureza (SUTTON, 1997, 2003). De acordo com Clive Sutton, "os historiadores e estudiosos da linguagem têm mostrado que esta [a linguagem] está fortemente implicada no processo de gênese e formulação das novas ideias" (SUTTON, 2003, p. 22).

Investigar a linguagem da ciência e os diferentes modos de pensamento apresentados pelos cientistas não é uma abordagem inédita. Considerando o contexto da Física, em particular, destacam-se os pensamentos e linguagens formais envolvidos em sua construção. As analogias formais e materiais no desenvolvimento dos modelos científicos (SILVA, 2007) e o papel da linguagem matemática no pensamento físico (KARAM, 2012; PIETROCOLA, 2002) são exemplos de pesquisas com este viés.

Ao discutir o papel epistemológico da matemática na Física, Pietrocola aponta que "ao contrário do que ocorre no cotidiano, a ciência, normalmente, vale-se da Matemática como forma de expressar seu pensamento" (PIETROCOLA, 2002, p. 89). De acordo com este autor, o uso da linguagem matemática se tornou, ao longo da história da Física, um critério de cientificidade, uma vez que "a incapacidade de expressar propriedades de sistemas em linguagem matemática inviabiliza mesmo a possibilidade de admiti-las como hipóteses para o debate científico" (PIETROCOLA, 2002, p. 89). Assim, considerando a própria identidade epistemológica da Física, a linguagem Matemática teria importante papel em seu ensino. Como aponta o físico Manoel Robillota, negligenciar ou dar papel secundário ao formalismo matemático "[...] corresponderia a apresentar aos estudantes uma caricatura pobre da Física, já que esta é estruturada em termos matemáticos e é praticamente impossível saber Física sem dominar essa estrutura" (ROBILLOTA, 1985, p. 7).

Mesmo considerando que o pensamento formal, especialmente aquele estruturado pela linguagem matemática, é fundamental para a constituição da ciência, particularmente da Física como a conhecemos hoje, podemos legitimamente nos perguntar se apenas a linguagem matemática é suficiente para estruturar o pensamento do cientista a ponto de permitir-lhe elaborar interpretações acerca da natureza. Assim, cabe questionar se pensamentos/linguagens que não são estritamente formais podem desempenhar papel importante na construção da ciência. Tendências atuais indicam que a linguagem não é uma mera ferramenta de descrição do mundo, mas sim o meio que dispomos para compreendê-lo. Clive Sutton $(1997,2003)$ tem criticado fortemente o uso da linguagem científica na escola, defendendo que há a necessidade de se dar maior ênfase à linguagem como sistema interpretativo, em detrimento ao que ele denomina de sistema de etiquetagem. Ou seja, para ele a linguagem está sendo trabalhada como se ela fosse um meio de informar objetivamente o que acontece independente dos seres humanos, em vez 
de trabalhá-la como "um meio de pôr as ideias à prova, para imaginar o que vai acontecer e para interpretar as situações" (SUTTON, 1997, p. 14).

Jerome Bruner (1997) considera que os seres humanos apresentam dois tipos básicos de pensamentos: o pensamento lógico-científico e o pensamento Narrativo. Para ele, estes pensamentos têm a função de organizar a experiência e podem apresentar-se de maneira complementar, não sendo possível reduzir um ao outro. Tendo em vista as considerações anteriores, sobre o eventual papel de pensamentos e linguagens não formais na construção da ciência e o caráter formal que identifica de maneira mais singular a linguagem da Física, aliado, ainda, ao apontamento teórico de Bruner, levantamos a questão central deste trabalho: Qual o papel do Pensamento Narrativo para a prática do cientista e como este tipo de pensamento pode se relacionar com pensamentos formais, estruturados pela linguagem Matemática?

Uma resposta possível a esta questão só pode ser dada considerando contextos bem delimitados da história do pensamento científico, para não incorrermos em generalizações indevidas. É preciso considerar que as ciências podem se desenvolver de diferentes formas quando se considera contextos históricos variados. Tendo isto em vista, este trabalho toma como foco de investigação o contexto de elaboração da Teoria da Relatividade Geral (TRG) pelo físico alemão Albert Einstein. Assim, nossa questão se circunscreve da seguinte maneira: Qual o papel das Narrativas e da Matemática no pensamento de Einstein no contexto de construção da Teoria da Relatividade Geral?

A escolha de Einstein, particularmente no contexto da TRG, se dá por alguns motivos:

- A obra de Einstein é notadamente perpassada por discussões filosóficas, o que torna o alemão um "cientista-filósofo" (PATY, 1993). Este autor refletiu e escreveu sobre o processo de criação de suas ideias, o que permite acesso a uma rica documentação.

- A TRG é reconhecida pelo elevado grau de matematização e por ter criado uma nova forma de interpretarmos a realidade física, especialmente em relação aos conceitos de espaço, tempo e gravidade.

- A obra de Einstein tem grande reconhecimento, tanto na comunidade científica como fora dela. Isto faz com que haja material de consulta em abundância, seja do próprio cientista, seja dos especialistas em sua obra.

O presente trabalho é uma abordagem teórica sobre o tema e, assim, privilegia a análise documental de fontes primárias e secundárias em sua elaboração. Nas próximas seções serão apresentados alguns aprofundamentos teóricos sobre o papel das narrativas e da matemática no desenvolvimento do pensamento. Em seguida, analisaremos o episódio histórico da gênese da TRG.

\section{O papel da matemática na construção da física}

A matemática pode desempenhar um papel descritivo na física, contudo, em algumas perspectivas epistemológicas esta pode não ser sua principal função. De acordo com Maurício 
Pietrocola “[...] a importância [da Matemática] está no papel estruturante que ela pode desempenhar quando do processo de produção de objetos que irão se constituir nas interpretações do mundo físico" (PIETROCOLA, 2002, p. 100). Neste sentido, a Matemática enquanto linguagem empresta sua estruturação ao pensamento científico para compor os modelos físicos sobre o mundo, ou seja, ela compõe a visão de mundo do cientista. De acordo com o autor, a escolha da matemática enquanto estruturadora da ciência reside, entre outras coisas, nas suas características de precisão, universalidade e lógica dedutiva (idem, p. 102).

A prática de olhar para os fenômenos da natureza através da matemática remonta à tradição grega. Os pitagóricos, por exemplo, acreditavam que o que é permanente, unitário, verdadeiro e, portanto, inteligível sob as aparências enganosas dos fenômenos, são suas proporções harmoniosas, expressas em números. A academia platônica, por sua vez, considerava que a realidade das aparências enganosas dos quatro elementos fundamentais - terra, ar, fogo e água - são as figuras geométricas perfeitas: tetraedro, cubo, octaedro e icosaedro. Para Platão, a realidade última eram as ideias, e neste mundo as formas geométricas, tornadas inteligíveis pelo pensamento matemático, eram essenciais. De acordo com Vargas (1996, p. 251), foi somente durante o período Helenístico que homens como Arquimedes deram origem à ideia de aplicação da geometria e da aritmética como instrumento de compreensão de fenômenos. Outro filósofo importante deste período foi Erastóstenes, quem, entre outras coisas, mediu a circunferência da Terra e estimou as distâncias e tamanhos do Sol e Lua, em particular, através da geometria. Ao final do período helenístico, Claudio Ptolomeu "utilizou intensivamente a matemática para a compreensão do movimento dos astros" (VARGAS, 1996, p. 252) e na Idade Média movimentos como o dos calculadores de Oxford defenderam a matematização da natureza.

Ainda que consideremos todo este importante contexto histórico aqui superficialmente sumarizado, é a partir do século XVII que a matemática ganha o reconhecimento mais próximo ao que hoje conhecemos na Física. Uma das figuras que representam este movimento é Galileu Galilei. De acordo com Vargas (1996), foi a obra Discursos e demonstrações matemáticas em torno de duas novas ciências, publicada em 1638, "quem tornou patente a nova função da matemática como análise dos fenômenos naturais" (VARGAS, 1996, p. 255). No entanto, de acordo com o filósofo francês Michel Paty (1995), Galileu ainda segue uma tradição pitagórica, em que a matemática era "concebida como um conhecimento que permitia uma leitura direta da natureza, da qual, precisamente, era a língua" (PATY, 1995, p. 234).

Contudo, de acordo com Paty (1995), o desenvolvimento histórico da Física substituiu esta "tradução matemática" da natureza por uma mediação física propriamente dita, isto é, a matematização tornou-se "inerente aos conceitos [físicos], constitutiva desses, que serve para construí-los" (PATY, 1995, p. 234). Considerando os rumos que a física tomou em direção à matematização, podemos levantar a seguinte questão: Por que a matemática é tão efetiva na física? Para Boniolo e Budinich (2005) essa é uma falsa questão, uma vez que não podemos considerar a matemática como um elemento externo à física, de modo a poder especular sobre 
sua eficiência. Para os autores, a Física contemporânea é constituída de signos físico-matemáticos que "não podem ser divididos em uma parte matemática e outra parte não matemática" (BONIOLO; BUNDINICH, 2005, p. 86).

Para Paty (1995), as teorias físicas fazem intervir o uso da matemática em diversos níveis, de modo que ela é, em diferentes casos, mais ou menos constitutiva dos conceitos físicos. Em um nível mais superficial a matemática seria usada como um instrumento descritivo, despojado de conteúdo físico, como é o caso da escolha de variáveis ou de unidades. Por outro lado, em um nível mais íntimo, a Matemática constitui o próprio conceito físico, como é o caso do conceito de velocidade, que é definida como uma taxa de variação do espaço no tempo (PATY, 1995, p. 251-252). Ainda de acordo com este filósofo, a força da utilização da matemática manifesta-se por seu resultado em predições. No século XVIII, por exemplo, a predição precisa da volta do cometa Halley surgiu como uma confirmação espetacular do sistema newtoniano, assim como o desvio da luz, observado no eclipse solar na Ilha Príncipe (África) e em Sobral (Brasil), em 1919, foi para a Teoria da Relatividade Geral.

A força de um modelo físico-matemático consiste também em sua capacidade de integrar uma descoberta experimental imprevista. A física de partículas é uma área vasta de exemplos neste sentido. Ricardo Karam (2012) entende esta característica como uma interpretação realista das entidades matemáticas. Um dos casos mais notáveis da história da física para exemplificar este uso da matemática é a previsão da existência de antipartículas, por Paul Dirac (1902-1984) em 1928, a partir da admissão de um valor negativo para a solução de sua equação de onda relativística, cuja comprovação experimental ocorreu com a detecção do pósitron em 1932 (KARAM, 2012, p. 12). Paty (1995) discute o caso do neutrino que, em um primeiro momento, era uma invenção matemática que servia como "um remédio desesperado para salvar as leis da energia e da estatística", segundo as palavras de Pauli, mas que ganhou status de uma partícula real (como o próton ou o nêutron) através de um processo que foi desde sua utilização no interior de teorias construídas à época, como a teoria de desintegração beta de Fermi, até, finalmente, sua detecção experimental.

A discussão sobre o papel da Matemática na Física, geralmente, é feita sob um ponto de vista histórico, tomando-se o cuidado de selecionar exemplos em contextos específicos. Karam (2012) afirma que "ao dissertar de maneira geral sobre o papel da Matemática na Física, sem definir um problema e um contexto histórico específico, corre-se o risco de se chegar a conclusões excessivamente reducionistas ou erroneamente generalizadas" (KARAM, 2012, p.12-13). Este apontamento indica a importância dos estudos de caso ${ }^{3}$ neste tipo de investigação, de acordo com a perspectiva da epistemologia histórica.

Embora a matemática estruture o pensamento do cientista e desempenhe um papel constitutivo dos conceitos físicos, características ainda mais latentes quando se considerada a Física Moderna (Quântica e Relatividade), acreditamos que somente a Matemática não permite

\footnotetext{
${ }^{3}$ Pesquisa concentrada em momentos bem delimitados da história, que permitam o aprofundamento das questões que estão sendo estudadas.
} 
que o cientista construa suas interpretações acerca da natureza. Ainda que a Física seja, em grande parte, uma ciência formal, ela também é empírica, ou seja, apresenta um compromisso com o mundo real, o que não necessariamente é verdade para a Matemática. Paty (1995) alerta para o cuidado a ser tomado com relação à supervalorização do papel da lógica matemática para a física.

\begin{abstract}
Pensar que, no raciocínio intermediário de tipo matemático, cada termo, cada relação tenha necessariamente uma transcrição física, significaria colocar em princípio que as entidades matemáticas são mais reais que a própria realidade física - o que nos levaria a uma ontologia pitagórica - e considerar que a lógica tem, por si mesma, esse poder de engendrar novas propriedades dos objetos físicos. Ao contrário, como Einstein percebera com muita propriedade, por si só, o pensamento lógico não pode nos fornecer conhecimento sobre o mundo da experiência: tudo o que conhecemos da realidade vem da experiência e nela resulta. Proposições puramente lógicas são completamente vazias em relação à realidade (PATY, 1995, p. 255).
\end{abstract}

Assim, torna-se necessário questionar se a interpretação do mundo natural não exige outras formas de linguagem na estruturação do pensamento. Para o escopo deste trabalho, cabenos investigar a relação da matemática com outra maneira de organizar as ideias, com outro modo de pensamento que não é estritamente formal: o pensamento narrativo.

\title{
III. Narrativas como modo de Pensamento
}

O interesse por narrativas no ensino de ciências tem sido crescente nos últimos anos. Particularmente, "há um amplo uso da narrativa na comunicação científica como uma forma de tornar a ciência mais relevante para o público em geral" (ESPINET et. al. 2012, p.1399, tradução nossa). Há uma variedade de abordagens sobre o tema, além de uma pluralidade de fundamentações teóricas a respeito do que constitui uma narrativa. Em geral, percebemos que os enfoques nas pesquisas em ensino de ciências não apresentam, de maneira direta, discussões de cunho epistemológico, isto é, discussões acerca de um potencial uso de Narrativas por parte dos próprios cientistas na produção do conhecimento da ciência (GURGEL, 2010).

Para uma fundamentação epistemológica das narrativas tomamos como base os trabalhos de Jerome Bruner (1997, 2001, 2014). Este autor defende que existem dois modos básicos de pensamentos, os quais ele chamou de pensamento lógico científico, também chamado de paradigmático, e o pensamento narrativo. Para ele, esses são dois modos de funcionamento cognitivo, que fornecem diferentes formas de ordenamento da experiência e de construção da realidade (BRUNER, 1997, p. 12). Enfatiza, ainda, que estes modos de pensamentos podem ser complementares, no entanto irredutíveis um ao outro.

Uma das principais distinções que Bruner faz entre o pensamento lógico-científico e o pensamento narrativo refere-se à relação que eles têm com a verdade. Enquanto o primeiro 
busca por verdades universais estabelecendo provas formais e empíricas, o segundo pretendese apenas verossímil.

Bruner propõe que a construção de narrativas pode fazer parte do desenvolvimento da ciência, abordando esta questão de maneiras diferentes ao longo de sua trajetória. Em um primeiro momento, sua análise é claramente influenciada pela visão epistemológica de Popper. O psicólogo norte-americano defende que muitas hipóteses científicas têm início como pequenas histórias ou metáforas, mas elas atingem sua maturidade científica através de um processo de conversão em verificabilidade, formal ou empírica (BRUNER, 1997, p. 13).

A ciência - particularmente a física teórica - também procede construindo mundos de um modo comparável, "inventando" os fatos (ou mundo) contra os quais a teoria deve ser testada. [...] Mas a criação do mundo envolvido em suas especulações é de uma ordem diferente da que a criação de histórias faz. A física deve acabar predizendo algo que é comprovadamente certo, não obstante o quanto ela possa especular. As histórias não têm tal necessidade de comprovabilidade (BRUNER, 1997, p.15).

Podemos notar que o distanciamento que Bruner faz entre as narrativas e a ciência está pautado, sobretudo, em uma visão contestável, do ponto de vista epistemológico, sobre o conhecimento científico. Para ele o falseacionismo de Popper é o principal critério para determinar o que é conhecimento científico. Com isto, afirma que "se aplicarmos o critério de Popper de falsificabilidade a uma história como teste de seu valor, seremos culpados de avaliação descontextualizada" (BRUNER, 1997, p. 16). De fato, a acusação de avaliação descontextualizada seria pertinente, no entanto, pode-se questionar se o critério de Popper seria o único para demarcar o que é científico. Nesta fase de seu pensamento o principal equívoco de Bruner é considerar que o conhecimento científico é capaz de predizer algo comprovadamente certo, algo que o próprio filósofo austríaco não defenderia. Tirada essa ilusão com resquícios positivistas, abre-se a possibilidade de as narrativas se aproximarem mais do processo de desenvolvimento do conhecimento científico.

Ao longo de sua trajetória, Bruner parece ter superado, ao menos em partes, sua visão de ciência pautada na epistemologia de Popper. No livro A cultura da Educação, publicado dez anos após sua primeira obra que tratava das narrativas, o autor afirma o seguinte:

[...] é possível falsificar uma grande quantidade de hipóteses, os historiadores da ciência deixam claro, sem se derrubar a teoria da qual podem ter derivado, o que sugeriu a muitos nos últimos anos que as grandes teorias da ciência talvez sejam mais parecidas com as histórias do que supúnhamos (BRUNER, 2001, p.120)

Bruner passa a entender que "[...] normalmente transformamos nossos esforços de compreensão científica na forma de narrativas ou, digamos, de "heurística narrativa"” (BRUNER, 2001, p.122). Com o termo heurística narrativa, o psicólogo estadunidense quer destacar uma característica essencial das narrativas: sua capacidade em lidar com situações problemáticas. A narrativa é, de acordo com o autor, um meio de encaminhar soluções a problemas, mas, 
principalmente, para encontrá-los. Neste sentido, Bruner aponta que: "a grande narrativa é um convite para descobrir problemas, não uma aula para resolvê-los. Ela diz respeito aos dilemas, às estradas por onde se caminha - mais aos nossos passos do que ao lugar onde se chega" (BRUNER, 2014, p. 30). Este processo passa por colocar em questão nossos conhecimentos tidos como certos, ou seja, a narrativa desafia nossa concepção do canônico, em uma espécie de dialética entre aquilo que era esperado e aquilo que veio a ocorrer (BRUNER, 2014, p. 2425). De acordo com o autor, "as histórias giram em torno de normas violadas. Isto já está claro e isto coloca os "problemas" no centro das realidades narrativas. As histórias que valem a pena ser contadas e interpretadas normalmente surgem a partir de problemas" (BRUNER, 2001, p. 136).

De acordo com Bruner, a narrativa é uma das principais maneiras que dispomos para interpretar a realidade. A etimologia da palavra narrar nos indica que a narrativa pode ir além de contar algo já sabido. Esta palavra deriva tanto de narrare, com o sentido mais restritivo de contar sobre algo, quanto de gnarus, que significa conhecer de um modo particular (BRUNER, 2014 , p. 37). Ou seja, a construção de narrativas pode ser entendida como uma maneira particular de conhecermos a realidade. Vale a ressalva que estamos falando de uma realidade construída e não um acesso direto à realidade primeira, como um realista ingênuo poderia pleitear.

Nosso acesso ao mundo é feito por mediações, através de construções simbólicas. Para Bruner, a narrativa é um desses meios de acesso. Ele defende que a narrativa é uma forma de organização do mundo exterior.

Fabricar histórias é o meio para nos conciliarmos com as surpresas e estranhezas da condição humana, para nos conciliarmos com a nossa percepção imperfeita desta condição. Histórias tornam o inesperado menos surpreendente, menos sinistro: elas domesticam a imprevisibilidade dando-lhe um verniz de banalidade (BRUNER, 2014, p. 100)

Bruner coloca a narrativa como a moeda comum entre o nosso self e o mundo social (CORREIA, 2003, p. 509), entre o individual e o cultural (GURGEL, 2010, p. 190). Assim, "explorar a natureza da narrativa, desde que sejamos sensíveis ao contexto em que foi revelada, seria explorar um modo de raciocínio" (CORREIA, 2003, p. 509). Este modo de raciocínio, que representa o individual e o cultural, permite que o novo surja, a partir da reconstrução do estabelecido, em um processo dialético entre imaginação e memória. Assim, podemos caracterizar a elaboração das narrativas como um processo de criação, com base na imaginação, mas que não é alheio à própria realidade e às formas culturais que são estabelecidas (GURGEL, 2010, p. 190).

Ao falar da interpretação narrativa da realidade, Bruner elabora uma questão fundamental: "O que, de fato, se ganha e o que se perde quando os seres humanos extraem sentido do mundo contando histórias sobre o mesmo, utilizando o modo narrativo para interpretar a realidade?" (BRUNER, 2001, p. 128). Para responder à tal questão, o autor apresenta o que ele chamou de universais que permitem à interpretação narrativa dar formas às realidades que 
criam. Para ele, esses universais são essenciais à vida em uma cultura. Ao todo, são nove elementos universais. Importante apontar que ao esboçar esses nove elementos, Bruner se deparou com o caráter inextricável da relação entre o pensamento e a linguagem.

Ao esboçar nove maneiras pelas quais a interpretação narrativa dá forma às realidades que criam, pensei ser impossível distinguir de maneira bem definida o que é um modo narrativo de pensamento e o que é um "texto" ou discurso narrativo. Cada um deles dá forma ao outro, do mesmo modo que o pensamento torna-se inextricável da linguagem que o expressa e que acaba moldando-o (BRUNER, 2001, p. 129).

A seguir, apresentamos uma síntese dos nove elementos universais propostos por Bruner:

1. Uma estrutura de tempo consignada: O tempo não é definido por um relógio, mas pelo desenrolar de eventos cruciais - pelo menos em começo, meio e fim. Bruner afirma que "o que está por trás de nossa compreensão do que é narrativa é um "modelo mental" de sua temporalidade - o tempo que é limitado não simplesmente por relógios, mas pelas ações humanamente relevantes que ocorrem dentro de seus limites" (BRUNER, 2001, p.129);

2. Particularidade genérica: As narrativas tratam de detalhes. As histórias são interpretadas como se se enquadrassem em gêneros e essas interpretações são influenciadas por contextos culturais e históricos. Mas o que são os gêneros? "Por um lado, um gênero 'existe' em um texto - em seu enredo e em sua forma de contar; por outro, ele 'existe' como uma forma de extrair sentido de um texto - como um tipo de "representação do mundo"' (BRUNER, 2001, p.130). Comédia, tragédia, romance, ironia e autobiografia são exemplos de gêneros. Para concluir, Bruner afirma que os gêneros "são formas culturalmente especializadas de vislumbrar a condição humana" (idem, p.131);

3. As ações têm motivos: O que acontece na narrativa nunca é por acaso, nem estritamente determinado por causa e efeito; os acontecimentos são determinados por crenças, desejos, teorias, valores e outros "estados intencionais"; "A busca na narrativa é por estados intencionais que se encontram "por trás" das ações: a narrativa busca motivos, não causas. Os motivos podem ser julgados, avaliados no esquema normativo das coisas" (ibidem, p.132);

4. Composição hermenêutica: Nenhuma história possui uma única interpretação exclusiva. "O objetivo da análise hermenêutica é dar uma explicação convincente e não contraditória do que significa uma história" (ibidem, p.132). Bruner conclui dizendo que "todo narrador possui um ponto de vista, e nós temos um direito inalienável de questioná-lo” (ibidem, p.133).

5. Canonicidade implícita: De acordo com Bruner, para que valha a pena uma narrativa ser contada, ela deve ir contra a expectativa, deve romper um roteiro canônico ou desviar-se do legitimado; 
6. Ambiguidade de referência: $\mathrm{O}$ tema do qual trata uma narrativa está sempre aberto ao questionamento. Para Bruner, a narrativa cria ou constitui sua referência, a realidade para qual aponta (ibidem, p. 134);

7. A centralidade do problema: Como já apontamos anteriormente, os problemas são centrais nas realidades narrativas. As narrativas que valem ser contadas normalmente surgem, de acordo com Bruner, a partir de problemas.

8. Negociabilidade inerente: Para Bruner, há uma negociação entre diferentes histórias concorrentes: "você conta sua versão, eu conto a minha, e raramente precisamos brigar para acertarmos a diferença" (ibidem, p.137). Esta característica, de acordo com o autor, é o que faz com que a narrativa seja tão viável na negociação cultural.

9. A extensibilidade histórica da narrativa: Pontos decisivos de mudança, acontecimentos chaves no tempo quando o novo substitui o antigo é o que torna a expansibilidade da história possível; "os "pontos decisivos de mudança" constituem os ingredientes cruciais neste traço da realidade narrativa" (ibidem, p. 138).

\section{Narrativa e Matemática na elaboração da Teoria da Relatividade Geral}

Analisaremos o papel da Matemática e das Narrativas na construção da ciência a partir de uma perspectiva historiográfica. Nossa análise foca predominantemente as fontes primárias, que no nosso caso foram textos de Albert Einstein sobre a Teoria da Relatividade Geral (TRG): artigos, cartas e livros em que o físico apresenta sua obra. Além disso, nossa análise baseou-se, de maneira indireta, em trabalhos de especialistas na obra de Einstein, como John Stachel, Jürgen Renn, Abraham Pais, Michel Paty e outros.

Renn (2007, p. 59-60) e Stachel (2002 c, p. 261) referem-se ao desenvolvimento da TRG como um drama em três atos. Stachel (2002 c, p. 261) descreve esses atos da seguinte maneira:

- ATO I (1907): A formulação do Princípio de Equivalência;

- ATO II (1912): Representação matemática do campo gravitacional por um tensor simétrico de segunda ordem, que entra no elemento de linha (dS) de um espaço-tempo quadridimensional;

- ATO III (1915): Formulação das equações de campo, agora padrão (now-standard), para o campo métrico, e o uso de sua solução esfericamente simétrica para explicar a precessão anômala do periélio de Mercúrio.

O primeiro passo para o desenvolvimento da TRG (ATO I) foi a busca pela extensão do princípio de relatividade. Em 1907, dois anos após publicar os artigos acerca do que viria a ser conhecida como Teoria da Relatividade Especial, Einstein apresentou discussões a respeito 
de um campo gravitacional estático ${ }^{4}$ (STACHEL, 2002 a, p. 227), em um artigo de revisão apresentado à revista alemã Jahrbuch. Esta discussão expunha argumentos que embasam o que hoje conhecemos como princípio de equivalência (PE). Um ponto importante para a formulação do PE foi a percepção de Einstein de que um corpo em queda livre não sente o próprio peso. Esta ideia, que inicialmente pode parecer despretensiosa pela simplicidade, desempenhou papel fundamental na elaboração da TRG. Einstein considerou este o pensamento mais feliz de sua vida (PAIS, 1993, p. 223), referindo-se a ele da seguinte maneira:

Estava sentado numa cadeira na repartição de patentes em Berna quando de súbito me ocorreu um pensamento: se uma pessoa cai livremente, não sente o próprio peso. Fiquei abismado. Este simples pensamento provocou-me uma impressão profunda. Impeliu-me para a teoria da gravitação (EINSTEIN apud PAIS, 1993, p. 225).

O PE é, basicamente, a chave para relacionar os referenciais acelerados com os referenciais inerciais sob a ação de um campo gravitacional. Ou seja, ele permite descrever as leis físicas para quaisquer referenciais, com ou sem aceleração, e leva à generalização do princípio de relatividade (os detalhes serão discutidos na subseção IV.I).

O PE começa a ser desenvolvido por Einstein em 1907, no artigo para a revista alemã Jahrbuch der Radioaktivitat und Eletronik, mas o mesmo só ganha uma formulação consistente anos depois. Em 1911, Einstein voltou a se dedicar fortemente ao problema da gravitação e da TRG, a propósito da curvatura da luz num campo de gravitação (PATY, 2008, p. 73), apresentado em seu artigo Sobre a Influência da Gravidade na Propagação da Luz publicado originalmente em 1911 (EINSTEIN, 1983a). Um dos principais resultados deste artigo foi a previsão da curvatura da luz, a partir do princípio de equivalência. Esta previsão pode ser entendida como semiclássica, uma vez que utiliza o PE, mas ainda está associada à ideia de potencial gravitacional escalar (newtoniano).

A partir de 1912 (ATO II), contudo, Einstein abandona a geometria euclidiana e passa a utilizar as recém desenvolvidas geometrias diferenciais, quando introduz um tensor métrico de 10 componentes como uma representação do potencial gravitacional, substituindo sua representação na física clássica como uma única função escalar (RENN, 2007, p. 59-60). Einstein percebe que precisava da teoria de invariantes e covariantes ${ }^{5}$ associada ao elemento diferencial de linha

\footnotetext{
${ }^{4}$ A Teoria da Relatividade Especial não lidava com os problemas da gravitação. Esta era uma limitação que Einstein percebeu e queria superar com o desenvolvimento da TRG.

5 Em matemática e em física teórica, invariância é uma propriedade de um sistema e suas grandezas, as quais permanecem imutáveis independentemente de transformações. A velocidade da luz, por exemplo, é uma grandeza invariante sob transformações de Lorentz. As equações de Maxwell são invariantes sob esse mesmo tipo de transformações, ou seja, a forma das equações de Maxwell não mudam quando fazemos transformações de Lorentz. A covariância pode ser entendida como uma generalização da propriedade de invariância para matemática de tensores. Einstein buscava, com a TRG, a covariância das equações de campo.
} 


$$
d s^{2}=g_{\mu \nu} d x^{\mu} d x^{v}
$$

no qual as dez quantidades $g_{\mu \nu}$ devem ser consideradas campos dinâmicos que, de algum modo, descrevem a gravitação. Até então, Einstein estava utilizando coordenadas gaussianas. A geometria de Riemann lhe foi apresentada por Grossmann que, no entanto, apontou para o fato de que as equações diferenciais da geometria de Riemann eram não lineares, o que ele considerava uma má característica. Para Einstein, na verdade, esta era uma grande vantagem (PAIS, 1993, p. 266).

De acordo com o próprio Einstein, o desenvolvimento para as equações covariantes foi decisivamente influenciado pelo experimento do disco rígido em rotação (que será discutido na subseção IV.II). Somente no final de 1915, Einstein pôde "representar a gravitação pelo tensor métrico de espaço-tempo em quatro dimensões ("equação de Einstein"), exprimindo assim plenamente o caráter geométrico da gravitação" (PATY, 2008, p. 76). Apresentamos abaixo a equação covariante do campo gravitacional, ou equação de Einstein.

$$
G_{\mu v}=\frac{8 \pi G}{c^{4}} T_{\mu v}
$$

O tensor $G_{\mu \nu}$ é chamado de tensor de Eisntein e depende do tensor de curvatura de Ricci (que não está representado nesta equação), do tensor métrico, que descreve a curvatura local do espaço-tempo, além da constante cosmológica ${ }^{6}$. A gravidade se dá em termos deste tensor métrico, que descreve as propriedades geométricas do espaço-tempo quadridimensional. Além das constantes desta equação (o número pi, a velocidade da luz no vácuo e a constante gravitacional, mesma da gravitação newtoniana), temos o tensor $T_{\mu \nu}$, chamado de tensor tensão-energia, que descreve a matéria e energia em um dado ponto do espaço-tempo. Ou seja, nesta equação temos do lado esquerdo uma referência à geometria do espaço-tempo, enquanto o lado direito faz referência à distribuição de energia e momento na malha espaço-temporal. Uma interpretação interessante desta equação é dada pelo físico John Wheeler, que dizia que "lendo da esquerda para direita, temos o espaço-tempo dizendo como a matéria deve se mover, lendo da direita para esquerda, temos a massa dizendo como o espaço-tempo deve se curvar" (CREASE, 2011, p.175).

A solução esfericamente simétrica da equação de Einstein resolveu um antigo problema da física newtoniana: a precessão do periélio de Mercúrio. Em termos de valores absolutos, a mecânica de Newton oferecia um resultado razoavelmente próximo ao observado. Havia uma discrepância de apenas 43" por século entre o valor previsto e o observado. A TRG, por sua vez, prevê um resultado em coerência com o que era observado. Os resultados teóricos

\footnotetext{
${ }^{6}$ Para detalhes sobre a história da constante cosmológica ver (BAGDONAS; ZANETIC; GURGEL, 2013).
} 
da TRG, da precessão do periélio de Mercúrio entre outros, em concordância com o mundo empírico foi um dos aspectos de sucesso desta teoria.

Em seguida, analisaremos os passos para a construção da TRG em maior detalhe. O pensamento de Einstein será reconstruído considerando-se sua ligação com o estilo narrativo empregado em seus escritos. Buscaremos demonstrar que as formulações matemáticas que basearam a elaboração da TRG estão relacionadas a um pensamento narrativo que buscava caracterizar conceitos físicos presentes nesta formulação. Para isso, Einstein elabora uma espécie de história que busca dar uma nova significação a entidades como o espaço, o tempo e a massa.

\section{IV-1 Narrativa e matemática no desenvolvimento do Princípio de Equivalência}

O PE é fundamental para a fundamentação do princípio da Relatividade Geral, o qual diz que "todos os corpos de referência K, K" etc. são equivalentes para a descrição da natureza (ou para a formulação das leis gerais da natureza), qualquer que seja seu estado de movimento" (EINSTEIN, 1999, p. 54).

Uma das motivações de Einstein para o desenvolvimento do PE era poder interpretar o resultado, já conhecido empiricamente, referente à igualdade entre massa gravitacional e massa inercial. Para interpretá-lo, Einstein constrói uma narrativa que envolve uma sequência de eventos com observadores em diferentes referenciais, com e sem aceleração constante. Em termos de construção textual, Einstein constrói um cenário ${ }^{7}$ onde uma história se desenvolve, no qual as entidades físicas envolvidas vão ganhando novos significados, coerentes com a visão da nova teoria que está sendo construída. Esta construção é tributária, de alguma maneira, ao que já era estabelecido, formando uma relação entre memória e imaginação, e que resulta na problematização de alguns canônicos, coerente com a interpretação narrativa da realidade, proposta por Bruner.

A elaboração de experimentos mentais a respeito do princípio de equivalência ocorre já no artigo publicado na revista Jarbuch der Radioaktivitat und Eletronik, em 1907, e é retomado no artigo de 1911, Sobre a influência da gravidade na propagação da luz. No artigo Os Fundamentos da Teoria da Relatividade Geral, publicado originalmente em 1916, Einstein constrói o cenário imaginando dois sistemas de referência, K e K”, da seguinte maneira:

Seja K um referencial de Galileu [inercial], isto é, um sistema de referência tal que, em relação a ele (e pelo menos no domínio quadridimensional considerado), uma massa suficientemente afastada de outras massas se desloca em movimento retilíneo e uniforme. Seja K" um segundo sistema de coordenadas que tem, em relação a K, um movimento de translação uniformemente acelerado. Teríamos então uma massa suficientemente afastada de outras massas animada de movimento acelerado relati-

\footnotetext{
7 De acordo com a conceituação de Gancho (1997), o cenário (ou "espaço”) tem como funções principais situar as ações das personagens e estabelecer com eles uma interação, quer influenciando suas atitudes, pensamentos ou emoções, quer sofrendo eventuais transformações provocadas pelas personagens.
} 
vamente a K", sendo a sua aceleração, tanto em grandeza como em direção, independente da sua composição material e do seu estado físico (EINSTEIN, 1983b, p. $145)$.

Estes dois sistemas de referência são os lugares imaginados por Einstein para o desenvolvimento de sua narrativa. Já neste momento podemos notar que a confecção do cenário deste experimento mental é tributária de um pensamento matemático, uma vez que ele está sendo formado usando sistemas de coordenadas cartesianas. Este cenário também é conceitual, uma vez que é construído a partir do uso de alguns conceitos físicos, particularmente o conceito de campo gravitacional que, como veremos, desempenha papel fundamental no desenvolvimento da narrativa.

O ponto mais importante do desenvolvimento desta etapa do pensamento de Einstein está no seguinte questionamento: Poderá um observador, em repouso relativamente a $K$ ”, inferir daqui que se encontra sobre um referencial "realmente" acelerado? (EINSTEIN, 1983b, p.145). A importância deste questionamento para o desenrolar do texto mostra a centralidade do problema na construção das narrativas, como proposto em um dos universais de Bruner.

Einstein entende que a resposta deve ser negativa. O raciocínio que se segue é o ápice da narrativa e traz uma nova interpretação para as massas inercial e gravitacional, que acabam se configurando como personagens nesta etapa.

Com efeito, o referido comportamento de massas que se movem livremente em relação a K" é susceptível de uma outra interpretação, igualmente boa, que é a seguinte: o referencial K" não está animado de movimento acelerado, mas existe um campo de gravidade no domínio espaço-temporal considerado, e é esse campo que origina o movimento acelerado dos corpos em relação a K” (EINSTEIN, 1983b, p. 145).

Para Einstein, o que torna possível esta interpretação do observador em K" é o fato de a experiência (isto é, verificarmos isto em fenômenos da natureza) nos ter ensinado que existe um campo de forças, o campo gravitacional, que possui a notável propriedade de comunicar a todos os corpos a mesma aceleração. Um indício desta igualdade era encontrado, por exemplo, nos experimentos de Eötvös, que Einstein cita em uma nota de rodapé de seu artigo de 1916. Com esta interpretação, Einstein entende que o "comportamento mecânico dos corpos em relação a K" é o mesmo que a experiência nos revela em relação a sistemas que estamos habituados a considerar como sistemas em "repouso", ou seja, como sistemas "admissíveis"” (EINSTEIN, $1983 b$, p. 145). Com isto, o referencial K" passa a ser um sistema legítimo para descrever as leis da física, tanto quanto o sistema de referência K ("inercial"), porque, em vez de um referencial com aceleração constante, ele pode ser considerado como um sistema em repouso, mas com a atuação de um campo gravitacional homogêneo. Isso implica que as massas consideradas até então como de naturezas diferentes, isto é, um tipo de massa dita inercial e outra gravitacional são, no fundo, duas faces da mesma moeda. O observador em $\mathrm{K}$ considera a massa distante como sendo inercial, no entanto, o observador em K" considera esta mesma massa como sendo 
gravitacional, pois ela está acelerada graças à ação de um campo de gravidade. Como ambos os sistemas são equivalentes, as massas também o são.

Consideramos que as massas inercial e gravitacional são personagens desta etapa do texto. Como apontou Gurgel (2010), o desenvolvimento da narrativa se configura não só de modo a caracterizar as personagens, mas também para compor as condições de sua entrada em cena. Ou seja, propor um cenário possível, neste caso estruturado por um pensamento matemático (sistemas cartesianos de referência, com e sem acelerações constantes/ com ou sem campos gravitacionais), e imaginar como essas personagens se comportam diante de diferentes situações, fez com que essas personagens ganhassem um novo significado: equivalência do ponto de vista físico, através de um contexto que permitiu que isto fosse evidenciado.

A partir de reflexões de Einstein sobre este capítulo do desenvolvimento da TRG, contidas em seu livro Notas Autobiográficas, defendemos que a caracterização das massas como personagens desta narrativa leva a considerações importantes do ponto de vista matemático, particularmente sobre a necessidade de uma nova maneira de encarar o significado métrico das coordenadas.

Começamos com um espaço vazio, sem campo, como é o caso - em relação ao sistema de inércia - na teoria da relatividade restrita, como a situação física mais simples que se pode imaginar. Se pensarmos agora em um sistema não-inerte introduzido no pressuposto de que o novo sistema é uniformemente acelerado contra o sistema da inércia (numa definição tridimensional) em uma direção (convenientemente definida), então existe, com referência a esse sistema, um campo gravitacional paralelo estático. O sistema de referência pode ser rígido, euclidiano, nas suas propriedades métricas tridimensionais. Mas o tempo em que o campo aparece como estático não é medido por relógios estacionários igualmente constituídos. Com esse exemplo, reconhecemos que o significado métrico imediato das coordenadas desaparece quando se admitem as transformações não-lineares das coordenadas. Contudo, essa admissão é obrigatória, se quisermos fazer justiça à igualdade da massa gravitacional e da massa inerte (EINSTEIN, 1982, p. 67).

O significado métrico das coordenadas é um dos canônicos que são questionados. $\mathrm{Na}$ TRE, o significado físico das coordenas é direto, uma vez que o grupo de transformações neste contexto é o grupo de Lorentz, que são transformadas lineares. Este significado se perde quando se assume a possibilidade de transformações não-lineares que, como afirma Einstein, faz-se necessário se quisermos levar a cabo o princípio de equivalência (PE). De acordo com Bruner, a construção de narrativas tende a violar alguns conhecimentos que tínhamos como certos, quebrando alguns canônicos.

No artigo de 1916, Fundamentos da Teoria da Relatividade Geral, Einstein indica as decorrências do PE para o comportamento da luz. No artigo de 1911, Sobre a Influência da Gravidade na Propagação da Luz, os pensamentos envolvidos nisto ficam mais claros. Depois de chegar à equivalência entre os referenciais K e K", de um ponto de vista da mecânica (acelerações de massas), Einstein se interessa nos desdobramentos desta equivalência para outros 
fenômenos físicos, uma vez que sua intenção é generalizar as leis da física, sejam leis da mecânica, do eletromagnetismo ou de qualquer outra teoria física. Einstein começa por discutir sobre a ponderabilidade da energia, considerando que a TRE não fornece nenhum argumento do qual se possa inferir que o peso de um corpo depende de seu conteúdo energético (como faz para a massa inerte). Propõe uma complementação ao cenário apresentado inicialmente, inserindo dois sistemas materiais $S_{1}$ e $S_{2}$, munidos de instrumentos de medida e que se encontram sobre o eixo z do referencial K, a uma distância h um do outro. Desta maneira o potencial gravitacional em $S_{2}$ é maior que em $S_{1}$, por construção. Tendo este cenário em mente, Einstein imagina a seguinte experiência:

Imaginemos que S2 emite para S1 uma certa quantidade de energia E sob a forma de
radiação. Admitamos ainda que as quantidades de energia são medidas em S1 e S2
com dispositivos que se mostram completamente idênticos quando são levados a um
mesmo local do sistema ze aí comparados (EINSTEIN, 1983a, p. 131).

Até este momento, Einstein não faz nenhuma consideração a priori sobre o comportamento da radiação na presença de um campo gravitacional homogêneo. Considerações a este respeito são feitas partindo do princípio de equivalência.

De acordo, porém, com o nosso postulado da equivalência de K e K”, podemos estabelecer, em vez do sistema K colocado no campo de gravidade homogêneo, um sistema K", que não está sujeito à gravidade, mas está animado de movimento uniformemente acelerado no sentido positivo do eixo $z$ do sistema $K$. Os sistemas materiais S1 e S2 supor-se-ão rigidamente ligados ao eixo do z de K" (idem).

Após esta consideração, Einstein adiciona mais um elemento ao cenário onde está se desenvolvendo a história: um terceiro sistema, $\mathrm{S}_{0}$, desprovido de aceleração, com relação a um referencial $K_{0}$. O processo de transferência de energia de $S_{2}$ para $S_{1}$ será apreciado de $S_{0}$, da seguinte maneira:

Admitamos que é nula a velocidade de $K$ ” em relação a $K_{0}$ no instante em que é emitida de $S_{2}$ para $S_{1}$ a energia de radiação $E_{2}$. A radiação atingirá $S_{1}$ quando tiver decorrido o tempo $h / c$ [h é a diferença de altura entre $S_{1}$ e $S_{2}$ e c é a velocidade da luz] (em primeira aproximação). Nesse instante, porém, $S_{1}$ possui, em relação a $K_{0}$, a velocidade $\gamma . h / c=v$ [〉 é a aceleração de K" em relação ao referencial em "repouso" $\left.\mathrm{K}_{0}\right]$ (ibidem).

A partir deste raciocínio, particularmente estruturado por um pensamento matemático, Einstein considera que a radiação que chega a $S_{1}$ não possui a energia $E_{2}$ com o qual foi emitida, mas sim uma energia maior. Este resultado foi obtido imaginando a situação em que a descrição física foi feita a partir de um referencial acelerado, K”. No entanto, utilizando o PE, Einstein considera que o resultado deve ser o mesmo se for considerado o sistema $\mathrm{K}$, desprovido de aceleração, mas dotado de um campo gravitacional. Assim, a energia com que a radiação chegará em $S_{2}$ dependerá da diferença de potencial gravitacional entre $S_{1}$ e $S_{2}$. 
Nesta etapa da narrativa surge uma nova característica da radiação: o redshift gravitacional. Portanto, a radiação pode ser entendida como uma personagem desta história, que teve uma característica importante evidenciada a partir de experiências mentais ocorridas em um cenário adequadamente construído. Os desdobramentos mais importantes desta etapa da narrativa ocorrem quando Einstein imagina as experiências mencionadas acima em termos de frequências, avaliadas com um relógio colocado em $\mathrm{S}_{2}$, que explicará o redshift.

[...] se um raio de luz for emitido em $S_{2}$, sob um determinado potencial gravítico, $e$ apresentar no instante da emissão a frequência $v_{2}$ - determinada com um relógio colocado em $S_{2}$ - então ele apresentará, quando chegar a $S_{1}$, uma outra frequência $v_{l}$ - medida com um relógio idêntico ao anterior colocado em $S_{I}$ (ibidem).

Um problema que se coloca nesta altura da narrativa é o seguinte: "como é que num processo permanente de transferência de luz de $S_{2}$ para $S_{1}$ pode chegar a $S_{1}$ um número de períodos por segundo diferente daquele que foi emitido em $\mathrm{S}_{1}$ ?" (EINSTEIN, 1983a, p.136). O encaminhamento dado por Einstein foi indicar que não podemos considerar $v_{2}$ e $v_{1}$ como frequências tomadas de modo simplista como números de períodos por segundo. O ponto central é que nada nos força a admitir que os relógios em $S_{1}$ e $S_{2}$, submetidos a diferentes potenciais gravitacionais, tenham de ser tomados com idênticos ritmos de funcionamento. Com isto, consideramos que os relógios são, também, personagens desta narrativa. A caracterização dos relógios como não tendo uma homogeneidade em sua medida de tempo, devido ao fato de suas medidas dependerem do potencial gravitacional, traz uma consequência importante: a quebra com um canônico extremamente importante para a TRE: a constância da velocidade da luz. Mais uma vez esta característica da interpretação narrativa da realidade, quebra da canonicidade, fica evidenciada nos textos de Einstein.

[...] para medir o tempo num local em que o potencial gravitico tenha o valor $\Phi$ relativamente a origem das coordenadas, deveremos utilizar um relógio que apresente - quando colocado naquela origem - um ritmo $\left(1+\phi / c^{2}\right)$ vezes mais lento que o do relógio utilizado para medir o tempo na referida origem. Sendo assim, se designarmos por $c_{0}$ a velocidade da luz na origem das coordenadas, então a velocidade da luz, c, num local de potencial gravítico $\Phi$ será dada por $c=c_{0}\left(1+\frac{\phi}{c^{2}}\right)$ (EINSTEIN, 1983a, p. 137).

A conclusão de Einstein, portanto, é que o "princípio da constância da velocidade da luz não é, pois, segundo esta teoria [TRG], válido na forma que usualmente se põe na base da teoria habitual da relatividade [TRE]" (idem).

A partir disto, Einstein calcula o desvio que a luz deve sofrer ao passar próximo ao sol. Ele chegou a um resultado de 0,83 segundo de arco. Como discutimos anteriormente, a possibilidade de fazer previsões é uma das importantes características da relação entre matemática e física. Einstein conclui seu artigo propondo aos astrônomos o desafio de observar suas previ- 
sões. Contudo, com o abandono da geometria euclidiana, discutido na próxima subseção, Einstein chega a uma nova previsão para o desvio da luz, exatamente o dobro da primeira previsão, que foi corroborada pelas famosas expedições do Eclipse Solar Total, em 1919.

A partir desta análise, entendemos que o pensamento narrativo foi essencial para a elaboração destes experimentos mentais, em particular, quando foram criados cenários em que seriam desenvolvidas as experiências. Os desenvolvimentos destas experiências foram, em diferentes eventos, caracterizando diferentes personagens: massas inercial e gravitacional (equivalência), radiação, relógios (suas medidas dependentes do campo gravitacional) e velocidade da luz (que não é mais tida como absolutamente constante, como na TRE). Vemos nesta sequência uma estrutura de tempo consignada, que não depende da marcação de tempo no sentido cronológico, mas do desenvolvimento de eventos encadeados, o tempo da narrativa. Primeiro, Einstein imaginou um cenário. Em seguida, imaginou como os observadores em K e K" poderiam dizer algo sobre seu estado de movimento, particularmente através da observação de massas aceleradas. Na etapa seguinte, Einstein imagina experiências com luz (radiação), que evidenciou algumas características importantes, como o redshift gravitacional, a influência do campo gravitacional no funcionamento de relógios e a velocidade da luz dependente do potencial gravitacional.

Em todas essas experiências, isto é, em todas as etapas da narrativa, o campo gravitacional apresentou-se como um importante elemento do cenário, permitindo que muitas dessas características que mencionamos pudessem ser evidenciadas. Neste sentido, não apenas as personagens são importantes na construção de uma história, mas, sobretudo, as condições de sua entrada em cena.

O pensamento matemático esteve presente na estruturação destas experiências mentais, particularmente através da noção de referencial cartesiano, mas também com a confecção de equações que possibilitaram quantificar, por exemplo, a influência da gravidade sobre o ritmo dos relógios e a curvatura da luz passando rasante ao sol. Notamos, portanto, que estes dois modos de pensamentos, narrativo e matemático, apresentaram-se neste contexto de maneira complementar, compondo os experimentos mentais acerca do princípio de equivalência. Isto é, tanto um quanto o outro foram indispensáveis para que os conceitos envolvidos pudessem ganhar uma nova significação física, de acordo com a teoria em processo de elaboração.

A elaboração do princípio de equivalência foi fundamental no desenvolvimento da TRG e é essencial para a compreensão de outros experimentos mentais que surgiram ao longo do processo de construção desta teoria. Analisaremos na próxima subseção um desses experimentos mentais, considerados por Stachel (2002b) como um "elo perdido" na história da TRG. Trata-se do experimento mental do disco rígido em rotação, que foi fundamental para que Einstein abandonasse a geometria euclidiana e considerasse a possibilidade de um espaço-tempo curvo. 


\section{IV-2 Narrativa e matemática no experimento mental do disco rígido em rotação}

Uma consequência importante dos trabalhos acerca da TRG é a nova interpretação da geometria do espaço-tempo, o que implica que "nesse novo universo, não há espaço e tempo absolutos, e a gravidade não é uma força - não é um puxão entre dois objetos -, mas uma propriedade do espaço e do tempo" (CREASE, 2011, p.175). Encontramos, nos textos analisados, construções que culminaram em problemas formais, principalmente com relação à geometria. Em particular, destacaremos experimentos mentais, cujos resultados implicaram na insuficiência da geometria euclidiana em lidar com os novos problemas físicos apresentados pela TRG.

Os experimentos mentais discutidos na seção anterior estão no coração do que Stachel (2002c) chamou de Ato I do desenvolvimento da TRG, que resultou na formulação da ideia básica da TRG: o princípio de equivalência. A principal motivação de Einstein era estender a validade do princípio de relatividade, que na TRE restringia-se aos referenciais inerciais, para quaisquer sistemas de referência. Como vimos na seção anterior, a gravitação foi a "ponte" que permitiu relacionar referenciais inerciais e referenciais com acelerações constantes.

Neste contexto de extensão do princípio de relatividade havia um tipo de referencial particularmente importante a ser considerado: os referenciais em rotação. Julian Barbour aponta que "se Einstein quisesse fazer algum progresso em sua empreitada para estender o princípio de relatividade [...], era claramente necessário para ele estender o argumento que usou em 1907, de aceleração retilínea uniforme, para rotação" (BARBOUR, 1992, p.130). A primeira evidência que se conhece sobre a necessidade e importância de tratar os referenciais em rotação na TRG, encontra-se em uma carta de Einstein à Sommerfeld, datada de 29 de Setembro de 1909, onde Einstein faz uma breve menção ao experimento mental do disco rígido em rotação (EINSTEIN, 1995).

O experimento mental do disco foi decisivo em dirigir a atenção de Einstein para as geometrias não-euclidianas e, assim, permitindo-lhe interpretar os fenômenos de gravidade como distorções do espaço-tempo. Como vimos na seção anterior, Einstein já considerava, no artigo de 1911, Sobre a Influência da Gravidade na Propagação da Luz, que o comportamento de relógios eram influenciados pela gravidade. O experimento mental do disco em rotação evidencia que, além dos comportamentos de relógios, a gravidade também influencia as medidas de réguas. Portanto, com estas construções surge um importante problema que envolve, particularmente, o pensamento matemático: as coordenadas espaço-temporais, no contexto da TRG, passam a não ter um significado físico direto como na física clássica e na TRE.

Novamente, Einstein se valeu dos pensamentos narrativo e matemático para construir suas experiências mentais. $\mathrm{O}$ pensamento narrativo age, sobretudo, como uma maneira de criar cenários possíveis onde as experiências se desenvolvem, destacando a importância de preparar as condições de entrada em cena das personagens. Cada etapa das experiências mentais corresponde a eventos da narrativa em que as personagens vão ganhando novos significados, coerentes com a teoria que está sendo construída. Consideramos também que, das experiências mentais analisadas, esta é a que apresenta um tipo de pensamento matemático mais profundo. Isto 
porque o pensamento físico neste contexto foi arrastado pelas formas matemáticas (PATY, 2005), uma vez que as geometrias não-euclidianas permitiram a Einstein interpretar os fenômenos de gravidade como sendo distorções no espaço-tempo, revelando o caráter geométrico da TRG.

O experimento mental do disco foi citado por Einstein em um artigo de 1912 (EINSTEIN 1996, p.96). Analisamos, no entanto, este experimento a partir do artigo fundador de 1916, Fundamentos da Teoria da Relatividade Geral. Einstein começa por criar um cenário, da maneira que se segue.

Num espaço livre de campos de gravidade introduzamos um sistema de referência de Galileu $\mathrm{K}(\mathrm{x}, \mathrm{y}, \mathrm{z}, \mathrm{t})$ e, além disso, um sistema de coordenadas K" (x", y", z", t") em movimento de rotação uniforme. Supõe-se em coincidência permanente as origens dos dois sistemas, assim como os seus eixos Z (EINSTEIN, 1983b, p. 147).

O cenário que Einstein cria, portanto, é composto principalmente por dois referenciais, com destaque para o referencial acelerado, em rotação (na abordagem do artigo fundador, Einstein trata o referencial K" apenas como um sistema em rotação, não o trata como um disco rodando). Na sequência disto, Einstein imagina uma circunferência desenhada no plano X-Y de $\mathrm{K}$ e considera que, por razões de simetria, a circunferência traçada em $\mathrm{K}$ também pode ser considerada uma circunferência no plano X"-Y" de K" (lembrando que a origem de ambos os referenciais coincidem permanentemente). Após esta etapa, Einstein imagina a primeira experiência: medir o perímetro e o diâmetro da circunferência centrada em K e K”.

Suponhamos agora que se mede o perímetro e o diâmetro desta circunferência com uma régua-unidade (infinitamente pequena em relação ao raio) e que se calcula o quociente dos resultados das medições (EINSTEIN, 1983b, p. 147).

Essas medidas trarão, do ponto de vista matemático, um grande resultado para a TRG. Se a medida for feita com a régua que está em repouso com relação a $K$, a razão entre perímetro e diâmetro será $\pi$. Contudo, se a medida for efetuada com a régua em repouso com relação a K”, então, a razão obtida será maior que $\pi$.

Reconhece-se isto facilmente quando se aprecia todo o processo de medição partindo do sistema "em repouso" $K$, e se tem em conta que a régua disposta ao longo da circunferência sofre a contração de Lorentz, ao passo que uma régua disposta ao longo do raio não a sofre (EINSTEIN, 1983b, p.148).

Este é o ponto alto da narrativa e diz respeito ao comportamento das réguas sobre um referencial em rotação. Vale ressaltar que Einstein parte de um resultado bem conhecido, a contração de Lorentz. Como citado anteriormente, a construção da narrativa se dá em uma espécie de dialética entre imaginação e memória. Ainda que Einstein esteja criando algo novo, ele não o faz sem base em conhecimentos anteriores, mas a partir de algo que já tem alguma validade (mesmo que esta validade seja colocada em xeque ao longo da história). 
Em uma correspondência trocada com Petzoldt, um filósofo positivista que escreveu a Einstein objetando o tratamento dado ao disco rígido em rotação, Einstein esclarece o porque a razão entre o perímetro e o diâmetro da circunferência deveria ser maior que $\pi$.

Vamos imaginar, para deixar claro para nós mesmos, uma foto tirada de $K_{0}$ [referencial em "repouso", equivalente ao que Einstein chamou de K no artigo de 1916]. Nesta foto a medida radial da régua tem um comprimento 1, contudo, a medida na tangente tem um comprimento $\sqrt{1-\left(v / c^{2}\right)}$. A circunferência do disco circular não é nada além do que o número de réguas-unidade tangenciais que estão presentes na foto ao longo da circunferência, cujo comprimento considerado a partir de $K_{0} e ́$ $U_{0 .}$ Então, $U=U_{0} / \sqrt{1-\left(v^{2} / c^{2}\right)}$ (EINSTEIN apud STACHEL, 2002b, p. 250).

Como não há contração de Lorentz na direção radial, podemos considerar que os raios são medidos igualmente pelos dois referenciais, isto é: $r=r_{0}$. Para o referencial "em repouso", podemos considerar, de acordo com a geometria euclidiana, que o comprimento da circunferência é: $U_{0}=2 \pi r_{0}$. Como Einstein estava interessado em encontrar a razão entre o comprimento da circunferência e o raio no referencial em rotação, basta dividir os dois lados da equação descrita na citação acima pelos raios medidos em cada referencial. Este raciocínio foi exatamente o empreendido por Einstein na correspondência com Petzoldt.

$$
\begin{aligned}
& \text { Então, [...], } U / r=U_{0} / r_{0}\left(1 / \sqrt{1-\left(v^{2} / c^{2}\right)}\right), \text { ou levando em conta (1) } \\
& {\left[U_{0}=2 \pi r_{0}\right]=2 \pi / \sqrt{1-\left(v^{2} / c\right)} \text {. (idem) }}
\end{aligned}
$$

Ou seja, a razão entre a circunferência do disco e seu raio é: $U / r=\gamma 2 \pi$. Como y é sempre maior que 1 , então, esta razão será maior que $2 \pi$ (considerando o diâmetro e não o raio, a razão será sempre maior que $\pi$ ). Este resultado coloca imediatamente a validade da geometria euclidiana em risco, quando se considera referenciais não inerciais, como é o caso do disco em rotação. Concluindo a experiência mental de medir o perímetro e o diâmetro das circunferências no referencial em rotação, Einstein afirma:

Sendo assim [a razão sendo maior que $2 \pi$ ], a geometria euclidiana não é válida no sistema $K$ " [referencial em rotação]; e o conceito de coordenada acima definido, visto que pressupõe a validade daquela geometria, também não é aplicável ao sistema K” (EINSTEIN, 1983b, p. 148).

Vale notar que, graças ao princípio de equivalência, o observador em K" pode concluir que está em um referencial em repouso, mas com a atuação de um campo gravitacional. Assim, a geometria euclidiana não é válida para referenciais em que atuam campos de gravidade. Com isso, passa a ser necessário descobrir a métrica de um ponto do espaço-tempo para que seja possível escrever as coordenadas no mesmo, pois com a presença de massa e energia o espaçotempo já não é mais plano, portanto, não vale mais a métrica de Minkowisk.

Na sequência, Einstein imagina experiências feitas com relógios. 
[...] imaginemos dois relógios idênticos, um na origem das coordenadas, outro sobre a circunferência, sendo observados a partir do sistema "em repouso" K. De acordo com um conhecido resultado da teoria da relatividade especial, o relógio colocado sobre a circunferência apresenta - quando observado de $K$ - um ritmo de funcionamento mais lento que o relógio colocado na origem, visto que aquele está animado de movimento e este não. Um observador situado na origem comum das coordenadas que fosse capaz de observar, por meio da luz, o relógio situado sobre a circunferência, verificaria portanto que este relógio se atrasa em relação ao relógio que tem junto de si. E, recusando-se a admitir que a velocidade da luz, no percurso em questão, dependa explicitamente do tempo, ele interpretará a sua observação dando-lhe o significado de que o relógio colocado sobre a circunferência tem "realmente" um ritmo mais lento que o relógio colocado na origem (EINSTEIN, 1983b, p. 148).

Com esta construção, Einstein chega à mesma significação de tempo da que mencionamos na seção anterior. Ou seja, esta construção também caracterizou a personagem tempo como dependente do lugar onde se encontra, isto é, dependente do potencial gravitacional.

Deste modo não lhe será possível [ao observador na origem comum dos referenciais] evitar uma definição de tempo que inclua o facto de o ritmo de um relógio depender do lugar em que se encontra (EINSTEIN, 1983b, p. 149).

Com estes experimentos mentais ocorridos no cenário imaginado por Einstein, disco em rotação, foi possível reconhecer alguns pontos importantes para o desenvolvimento da TRG, particularmente relacionados a problemas matemáticos: dificuldade em estabelecer as coordenadas espaço-temporais. Novamente, portanto, consideramos que os pensamentos narrativo e matemático foram complementares no contexto de experimentos mentais de Einstein. Com esses experimentos mentais, em que a história se desenvolveu de forma que as personagens "réguas" e "relógios" fossem caracterizadas, Einstein concluiu o seguinte:

Chegamos assim a esta conclusão: na teoria da relatividade geral não é possível dar às grandezas espaço e tempo definições que permitam a medição direta de diferenças de coordenadas espaciais por meio de uma régua-unidade e a de intervalos de tempo por meio de um relógio-padrão.

Assim, o processo até agora utilizado para estabelecer coordenadas, de uma maneira determinada, no contínuo espaço-temporal, torna-se impraticável, e não parece haver nenhum outro caminho que permita encontrar sistemas de coordenadas de tal forma adequados ao universo quadridimensional que da sua aplicação se pudesse esperar para as leis da natureza uma formulação particularmente simples. Nada mais resta, por conseguinte, que considerar como equivalente em princípio para a descrição da natureza todos os sistemas de coordenadas que se possam imaginar (EINSTEIN, 1983b, p. 149).

Com isto, fica clara para Einstein a exigência de covariância geral para as equações da TRG, isto é, as leis da natureza deveriam ser descritas por equações que tenham validade em todos os sistemas de coordenadas, sendo covariantes em relação a toda e qualquer substituição. Satisfazer esta exigência de covariância geral implica satisfazer, também, o postulado da rela- 
tividade geral "porque em todas as substituições estão sempre necessariamente incluídas aquelas que correspondem a todos os movimentos relativos dos sistemas de coordenadas" (EINSTEIN, 1983b, p. 149).

O problema de se definirem as coordenadas espaço-temporais teve centralidade na construção da história analisada, em que experimentos mentais foram feitos em um cenário construído: referencial em rotação. A centralidade do problema é uma importante característica das narrativas, configurando-se como um dos universais da interpretação narrativa da realidade (BRUNER, 2001). Mais uma vez a construção dessas histórias mostrou uma relação dialética entre memória e imaginação, permitindo que uma nova interpretação da natureza surgisse. Einstein valeu-se dos resultados da TRE, em especial a contração de Lorentz na direção do movimento e a dilatação temporal, para lidar com situações novas, do ponto de vista da validade da relatividade, ou seja, em referenciais não-inerciais. Isto resultou na contestação de um importante canônico: a geometria euclidiana. Esta característica também versa com um dos universais de Bruner, a canonicidade implícita (BRUNER, 2001). As construções realizadas a partir de experimentos mentais permitiram a Einstein concluir que seria necessário buscar novas geometrias para garantir a exigência de covariância geral, ou, em outras palavras, para estender o princípio de relatividade. Portanto, notamos que os pensamentos narrativo e matemático se apresentaram, novamente, de maneira complementar.

\section{Considerações finais}

O objetivo central deste trabalho foi o de discutir o papel de diferentes tipos de linguagens e pensamentos no processo de elaboração do conhecimento científico. Para tal, focamos nossa pesquisa no papel que a narrativa e a matemática desempenharam na elaboração de alguns conceitos da Teoria da Relatividade Geral de Einstein. Nosso estudo historiográfico não visou a didatização do estudo de caso selecionado, embora ele possa embasar eventuais trabalhos futuros que pretendam inserir tópicos de história da Teoria da Relatividade Geral em aulas de Física.

A partir da investigação acerca da elaboração da TRG, focando particularmente na construção de alguns experimentos mentais, consideramos que, embora o pensamento matemático tenha uma identificação muito grande com o desenvolvimento do conhecimento físico, principalmente no contexto da física moderna, o pensamento narrativo também desempenhou um papel importante na estruturação do pensamento de Einstein. A principal contribuição do pensamento narrativo foi trazer a possibilidade de criar cenários onde se desenvolveram os experimentos mentais, cujas caracterizações das personagens principais das histórias construídas resultaram em novas significações de entidades físicas.

O pensamento narrativo permitiu, em certa medida, a criação de realidades significantes. Ou seja, ao longo das narrativas as personagens ganhavam novos significados físicos coerentes com a teoria que estava surgindo. Essas caracterizações/significações, ocorridas dentro 
da narrativa, ganharam uma espécie de "direito à realidade", passando a compor nossas interpretações acerca do mundo físico. Notamos que tão importante quanto as personagens da narrativa, é a elaboração das condições de sua entrada em cena.

Notou-se, também, a importância do pensamento matemático na estruturação dos experimentos mentais analisados, particularmente nos experimentos do disco em rotação. Com isto, concluímos que os dois modos de pensar analisados, narrativo e matemático, embora bastante distintos, são complementares no contexto da gestação da TRG. Portanto, consideramos que pensamentos que não são estritamente formais, como é o caso do pensamento narrativo, também desempenham papel importante na atividade do físico, pelo menos no caso dos experimentos mentais analisados.

A identificação destes dois modos de pensamento na física tem particular relevância para o seu ensino. Com relação ao pensamento matemático, concluímos, em concordância com o que vem sendo defendido na literatura, que deve ser dada especial atenção para que não ensinemos a física de maneira apenas técnica, passando uma imagem aos estudantes de que a matemática serve somente como uma boa ferramenta para resolver os problemas de física, uma ferramenta apenas que articula seus conceitos. O poder que a matemática exerce no pensamento do físico está relacionado, principalmente, ao seu papel estruturante e não ao seu papel meramente descritivo (PIETROCOLA, 2002), ou seja, a matemática é constitutiva dos conceitos físicos (PATY, 1995).

Entendemos que considerar a relevância do pensamento narrativo, por sua vez, traz à luz a dimensão criativa do cientista em seu desafio de interpretar os fenômenos da natureza. Isto pode ser evidenciado quando Einstein cria cenários diversos onde as personagens das narrativas (entidades físicas) ganham novos significados. Portanto, a despeito de sua vital importância, o pensamento matemático por si só não é suficiente para o cientista elaborar interpretações acerca da natureza.

Além do que foi dito acima, sobre a importância do pensamento narrativo no processo criativo do cientista, consideramos que este tipo de pensamento é mais geral, ou seja, ele se apresenta em outras formas de organização de conhecimento, em outras formas de ordenar nossas experiências. Com isto, este tipo de pensamento pode ser utilizado como uma aproximação entre os estudantes e o conhecimento científico, enfatizando, sobretudo, o caráter criativo da atividade científica. Neste sentido, as narrativas atendem, ao menos parcialmente, à condição de trabalhar o conhecimento científico de um ponto de vista mais coerente com relação à natureza do fazer científico. Em particular, a criação de cenários possíveis onde novas significações físicas são construídas mostra que o trabalho do cientista não é um desvelar dos mistérios da natureza, mas a proposição de interpretações coerentes com a realidade.

O desenvolvimento das histórias presentes nos experimentos mentais que analisamos tiveram como personagens principais conceitos físicos chaves que foram ganhando novos significados, coerentes com a nova teoria que estava sendo construída. Essas personagens foram: 
massas inercial e gravitacional, na primeira parte da narrativa que resultou no princípio de equivalência. Radiação e Relógio, que ganharam uma nova significação frente às suas dependências de potenciais gravitacionais. Relógios e réguas nos experimentos do disco em rotação, cuja significação mostrou que as coordenadas espaço-temporais não apresentavam um significado físico direto, como na TRE. Considerando isto, classificamos o tipo de narrativas que identificamos na gestação da TRG, como Narrativas Conceituais, devido ao seu funcionamento como forma de caracterizar conceitos científicos que atuam como personagens no desenvolvimento de histórias, cuja criação de cenários possíveis permite a formulação de experimentos mentais. O pensamento Matemático, em todas essas construções, estruturaram as ideias de Einstein.

Considerando o papel de cada um desses tipos de pensamentos, é impossível reduzir um ao outro. A Matemática tem uma identidade maior com o conhecimento físico, mas defendemos, com base em nossa análise, que estes dois tipos de pensamentos se apresentam, no contexto de gestação da TRG, em uma espécie de dualidade. Eles atuam, sobretudo, de maneira complementar na elaboração de experimentos mentais, que resultaram na caracterização de importantes conceitos da Física.

Consideramos que devemos proporcionar aos nossos alunos a possibilidade de articular um pensamento de tipo científico para compor suas visões de mundo frente à sociedade que estes são atuantes. Acreditamos que trabalhar com narrativas pode ser uma maneira interessante para que eles criem cenários relevantes onde surjam problemas, de caráter científico, que possam ser encaminhados de acordo com as inúmeras possibilidades de desenvolvimento de uma narrativa, utilizando, inclusive, a matemática como uma forma de encaminhar estes problemas

Com relação ao ensino da TRG, em particular, nossa investigação mostrou que os experimentos mentais sobre o disco em rotação são muito importantes, embora se dê ênfase apenas aos experimentos mentais no "elevador de Einstein", isto é, os experimentos mentais feitos sobre um referencial com aceleração retilínea e uniforme. A TRG de Einstein se destacou, tanto dentro quanto fora da comunidade científica, pelo papel central de teorias matemáticas sofisticadas e recentes à época, em sua formulação e estruturação. Nossa investigação historiográfica indicou que o pensamento narrativo que estruturou os experimentos mentais desenvolvidos no cenário de um referencial em rotação, foi essencial para que Einstein considerasse a necessidade de abandonar a geometria euclidiana, tendo seu pensamento sido arrastado pelas formas matemáticas neste contexto. Isto fez com que fosse possível para ele interpretar os fenômenos de gravidade como distorções da malha espaço-temporal. Assim, os experimentos mentais sobre o referencial rodando, estruturado pelos pensamentos narrativo e matemático, tem uma profunda relevância histórica e conceitual.

As características do espaço-tempo, especialmente sua curvatura, são muito enfatizadas no ensino da TRG. No entanto, o "elo perdido" (STACHEL, 2002b) na história da gênese desta teoria, ou seja, o experimento mental sobre o disco em rotação, que levou Einstein às geometrias não-euclidianas, ainda é pouco conhecido e explorado no ensino da TRG. Um desdobramento da nossa pesquisa foi apresentar subsídios para que esse importante experimento 
mental possa, eventualmente, ser inserido no ensino da TRG, especialmente se a história da ciência é tida como enfoque educacional. Por fim, esperamos que a análise historiográfica apresentada neste trabalho possa contribuir para eventuais trabalhos futuros que estejam interessados em inserir tópicos de história da TRG no ensino da Física.

\section{Referências Bibliográficas}

BAGDONAS, A.; GURGEL, I.; ZANETIC, J. O grande erro de Einstein, a descoberta da expansão do universo e as reconstruções racionais da cosmologia. In: SIMPÓSIO NACIONAL DE ENSINO DE FÍSICA, XX, 2013, São Paulo. Atas... São Paulo: SBF, 2013.

BARBOUR, J. Einstein and Mach"s Principle. In: EISENSTAEDT, J.; KOX, A. (Org.). Studies in the History of General Relativity 3. Boston: Birkhäuser, 1992. cap. 9, p. 125-153.

BONIOLO, G.; BUDINICH, P. The Role of Mathematics in Physical Sciences and Dirac"s Methodological Revolution. In: BONIOLO, G; BUDINICH, P.; TROBOK, M (Org.). The Role of Mathematics in Physical Sciences: Interdisciplinary and Philosophical Aspects. Dordrecht: Springer, 2005. cap. 5, p. 75-96.

BRUNER, J. Realidade mental, mundos possíveis. Tradução: Marcos A. G. Domingues. Porto Alegre: Artes Médicas, 1997. 216 p.

BRUNER, J. A cultura da educação. Tradução: Marcos A. G. Domingues. Porto Alegre: Artmed Editora, 2001. 186 p.

BRUNER, J. Fabricando histórias: Direito, Literatura, Vida. Tradução: Fernando Cássio. São Paulo: Letra e Voz, 2014. 137 p.

CORREIA, M. A constituição social da mente: (re)descobrindo Jerome Bruner e construção de significados. Estudos de Psicologia, Natal, v. 8, n. 3, p. 505-513, set. 2003.

CREASE, R. As grandes equações: a história das fórmulas matemáticas mais importantes e os cientistas que as criaram. Tradução: Alexandre Cherman. Rio de Janeiro: Zahar, 2011. $280 \mathrm{p}$.

EINSTEIN, A. Notas Autobiográficas. Tradução: Aulyde Soares Rodrigues. Rio de Janeiro: Nova Fronteira, 1982. 88 p.

EINSTEIN, A. Sobre a Influência da Gravidade na Propagação da Luz. In: LORENTZ, H.A.; EINSTEIN, A.; MINKOWSKI, H. (Org.) O Princípio da Relatividade: Textos Fundamentais da Física Moderna I. Lisboa: Fundação Calouste Gulbenkian, 1983a, p.127-140. 
EINSTEIN, A. Os Fundamentos da Teoria da Relatividade Geral. In: LORENTZ, H. A.; EINSTEIN, A.; MINKOWSKI, H. (Org.) O Princípio da Relatividade: Textos Fundamentais da Física Moderna I. Lisboa: Fundação Calouste Gulbenkian, 1983b, p. 141-214.

EINSTEIN, A. 179. To Arnold Sommerfeld. In: BECK, A.; HOWARD, D. (Org.) The collected papers of Albert Einstein 5. New Jersey: Princeton University Press, 1995. p. 146-147.

EINSTEIN, A. The Speed of Light and the Statics of the Gravitational Field. In: BECK, A.; HOWARD, D. (Org.) The collected papers of Albert Einstein 4. New Jersey: Princeton University Press, 1996. p. 95-106.

EINSTEIN, A. A teoria da Relatividade Especial e Geral. Tradução: Carlos Almeida Pereira. Rio de Janeiro: Contraponto, 1999. 136 p.

ESPINET, M.; IZQUIERDO, M.; BONIL, J.; DE ROBLES, S. The Role of Language in Modeling the Natural World: Perspectives in Science Education. In: FRASER, B. J.; TOBIN, K. G.; MCROBBIE, C. (Ed.) Second International Handbook of Science Educantion. New York: Springer, 2012, cap. 89, p. 1385-1403.

FLÔR, C.; CASSIANI, S. O que dizem os estudos da linguagem na educação científica? Revista Brasileira de Pesquisa em Educação em Ciências, Belo Horizonte, v. 11, n. 2, p. 67 86, jan. 2011.

GURGEL, I. Elementos de uma Poética da Ciência: Fundamentos Teóricos e Implicações para o Ensino de Ciências. 2010. 301 p. Tese (Doutorado em Educação) - Faculdade de Educação, USP, São Paulo.

KARAM, R. Estruturação matemática do pensamento no ensino: Uma ferramenta teórica para analisar abordagens didáticas. 2012. 275 p. Tese (Doutorado em Educação) - Faculdade de Educação, USP, São Paulo.

LEMKE, J. Aprender a Hablar Ciencia: Lenguaje, aprendizaje y valores. Tradução: Ana García; Benilde García; Frida Barriga; Irene Muriá; Marco Rigo; Gerardo Hernández. Barcelona: Paidós, 1997. 272 p.

PAIS, A. Subtil é o senhor: vida e pensamento de Albert Einstein. Tradução: Fernando Parente; Viriato Esteves. Lisboa: Gradativa publicações, 1993. 665 p.

PATY, M. Einstein Philosophe: la physique comme pratique philosophique. Collection Philosophie d"Aujourd"hui. Paris: Presses Universitaires de France, 1993. 584 p.

PATY, M. A matéria roubada: A apropriação crítica do objeto da Física contemporânea. Tradução: Mary Amazonas Leite de Barros. São Paulo: Edusp, 1995. 320 p. 
PATY, M. Einstein e o papel da matemática na física. In: BROLEZZI, A. C.; ABDOUNOUR, O. J. (Org.). SEMINÁRIO PAULISTA DE HISTÓRIA E EDUCAÇÃO MATEMÁTICA, 1, 2005, São Paulo. Atas... São Paulo: IME - USP, 2005, p. 33-56.

PATY, M. Einstein. Tradução: Mário Laranjeira. São Paulo: Estação liberdade, 2008. 152 p.

PIETROCOLA, M. A Matemática como estruturante do conhecimento físico. Caderno Catarinense de Ensino de Física, Florianópolis, v. 19, n. 1, p. 89-109, ago. 2002.

RENN, J. (2007). Classical Physics in Disarray: The Emergence of the Riddle of Gravitation. In: RENN, J. (Ed.) The Genesis of General Relativity: Einstein"s Zurich Notebook Introduction and source. Dordrecht: Springer. p. 21-80. v.1.

ROBILOTTA, M. Construção e realidade no ensino de física. São Paulo: IFUSP, 1985. Publicação interna.

SALEM, S. Perfil, evolução e perspectivas da pesquisa em ensino de física no Brasil. 2012. 315 p. Tese (Doutorado em Ciências) - Instituto de Física, Instituto de Química, Instituto de Biociências, Faculdade de Educação, USP, São Paulo.

SILVA, C. C. The Role of Models and Analogies in the Eletromagnetic Theory: a Historical Case Study. Science \& Education, v. 16, n. 7-8, p. 835-848, Ago. 2007.

STACHEL, J. Einstein"s Odyssey: His Journey from Special to General Relativity. In: STACHEL, J. (Org.) Einstein from "B" to "Z". Einstein Studies, v. 9. Boston: Birkhäuser, 2002a. p. 225-232.

STACHEL, J. The Rigidly Rotation Disk as the "Missing Link" in the History of General Relativity. In: STACHEL, J. (Org.) Einstein from "B" to "Z". Einstein Studies, v. 9. Boston: Birkhäuser, 2002b. p. 245-260.

STACHEL, J. The first two acts. In: STACHEL, J. (Org.) Einstein from "B" to "Z". Einstein Studies, v. 9. Boston: Birkhäuser, 2002c. p. 261-292.

SUTTON, C. Ideas sobre la Ciencia e Ideas sobre el Lenguage. Alambique Didactica de las Ciencias Experimentales, n. 12, p. 8-32, jun. 1997.

SUTTON, C. Los Professores de ciencias como Professores de Lenguage. Enseñaza de las Ciencias, Barcelona, v. 21, n. 1, p. 21-25, mar. 2003.

VARGAS, M. História da matematização da natureza. Estudos Avançados, São Paulo, v. 10, n. 28, p. 249- 276, set/dez. 1996. 